\title{
Analysis of Geospatial Distribution of State-Sector Hospitals in Sri Lanka
}

\author{
by \\ BCV Senaratna
}

Thesis submitted to the University of Sri Jayewardenepura for the award of the Degree of Master of Science in Geographic Information Systems and Remote Sensing on 10th June 2014 


\section{Declaration by the candidate}

I hereby certify that the work described in this thesis was carried out by me under the supervision of Prof. Krishan Deheragoda of Department of Geography, University of Sri Jayewardenepura and Dr. WAA Wijayasiri of Department of Community Medicine, University of Sri Jayewardenepura and a report on this has not been submitted in whole or in part to any other university or institution for anther Degree/Diploma.

\section{$15 / 08 / 2014$}

Date

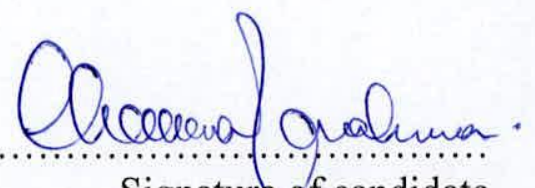

Signaturk of candidate

I/We certify that the above statement made by the candidate is true and that this thesis is suitable for submission to the University for the purpose of evaluation.

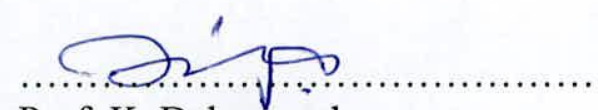

Prof. K. Deheragoda

Department of Geography, University of Sri Jayewardenepura.

is. $1.09 .6 .0 .14 \%$

Date

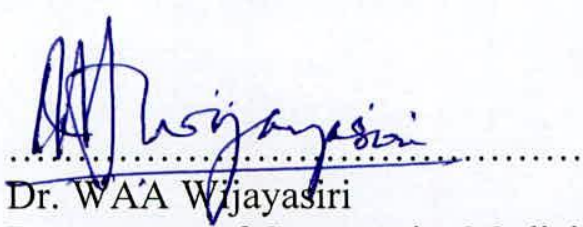

Department of Community Medicine, University of Sri Jayewardenepura.

15. 08,2014

Date 


\section{Contents}

Page

Title page

I

Declaration by the candidate $\quad$ II

Contents

List of tables $\quad$ VI

List of figures $\quad$ VII

Acknowledgements $\quad \mathrm{X}$

$\begin{array}{ll}\text { Abstract } & \text { XI }\end{array}$

1. Introduction 1

1.1 Evolution of healthcare services in Sri Lanka 1

1.2 Present status and classification of state-sector healthcare services 2

1.3 Distribution of curative healthcare institutions/hospital 4

1.4 Rationale $\quad 5$

$\begin{array}{ll}1.5 \text { Objectives } & 6\end{array}$

$\begin{array}{ll}\text { 1.5.1 General objective } & 6\end{array}$

1.5.2 Specific objectives $\quad 6$

$\begin{array}{ll}\text { 2. Literature review } & 7\end{array}$

2.1 Healthcare delivery system of Sri Lanka and its outcomes $\quad 8$

2.2 Distribution of healthcare resources and use of Geographic Information

$\begin{array}{lr}\text { Systems (GIS) in analysis of population correlates } & 9\end{array}$ 
3.3 Creation of required data from the secondary data sources

3.3.3 Creation of roads network layer

3.4 Data analysis

3.4.1 Description of types of hospitals and their distributions in different districts

3.4.2 Description of population in different districts and homestead areas

3.4.3 Description of distribution of hospitals within different districts and in relation to district populations

3.4.4 Description of catchment populations for each hospital regardless of districts

of location

3.4.5 Proximity analysis between neighbouring hospitals

3.4.6 Accessibility analysis for hospitals

4. Results

4.1 Types and the number of hospitals used in the analysis and their basic distribution

4.2 Distribution of population of Sri Lanka within districts and homesteads 
4.5 Feeding (by smaller hospitals) and drainage (to larger hospitals) patterns of hospitals

4.6 Accessibility of hospitals via existing main roads

\section{Discussion}

5.1 Distribution of hospitals within districts

5.2 Distribution of hospitals in relations to populations and population densities

5.3 Proximity of hospitals to one another

5.4 Accessibility of hospitals through existing roads network

5.5 Limitations of the study

6. Conclusions and Recommendations

6.1 Conclusions

6.1.1 Distribution of state sector hospitals in Sri Lanka

6.1.2 The relationship of the distribution of state sector hospitals to the population and population density of the relevant districts

6.1.3 Proximity of hospitals to each other

6.1.4 Accessibility of hospitals via existing main roads

6.2 Recommendations

\section{References}




\section{List of Tables}

Page

Table 1. Different types of hospitals included in the analysis

Table 2. Distribution of different categories of hospitals between the districts

Table 3. The average of distance between two hospitals of same or different types within each district 


\section{List of Figures}

Page

Figure 1. Distribution of the population in districts 30

Figure 2. Population density of districts $\quad 31$

Figure 3. Comparison of total populations and population densities in districts 32

Figure 4. Distribution of homesteads in districts 33

Figure 5. Comparison of land extent, homesteads extent and homesteads as a proportion of total land extent for each district 34

Figure 6. Population density in homesteads of each district 36

Figure 7. Comparison between general and homestead population densities for each district

Figure 8. Distribution of all hospitals in 25 districts relative to homesteads 39

Figure 9. Number of people per hospital in each district $\quad 40$

Figure 10. Number of DHCs per district $\quad 41$

Figure 11. Number of people per DHC within each district $\quad 42$

Figure 12. Number of DHBs per each district $\quad 43$

Figure 13. Number of people per DHB within each district 44

Figure 14. Number of DHAs per district $\quad 45$

Figure 15. Number of people per DHA within each district 46

$\begin{array}{ll}\text { Figure 16. Number of BHBs per district } & 47\end{array}$

Figure 17. Number of people per BHB within each district $\quad 48$

Figure 18. Number of BHAs per district $\quad 49$ 
Figure 19. Number of people per BHA within each district

Figure 20. Number of DGHs per district

Figure 21. Number of people per DGH within each district

Figure 22. Number of PGHs per district

Figure 23. Number of people per PGH within each district

Figure 24. Number of THs per district

Figure 25. Number of people per $\mathrm{TH}$ within each district

Figure 26. Catchment population for each hospital regardless of district it is located

Figure 27. Mean of the catchment population for hospitals within a district

Figure 28. Catchment populations for DHs

Figure 29. Catchment populations for $\mathrm{BHs}$

Figure 30. Catchment populations for GHs

Figure 31. Catchment populations for THs

Figure 32. Number of beds in all hospitals in each district

Figure 33. Number of beds in all hospitals in each district

Figure 34. Distance between one hospital and its nearest neighbour

Figure 35. Proximity of DHs to higher level hospitals (BHs, GHs, or THs)

Figure 36. Proximity of BHs to higher level hospitals (GHs or THs)

Figure 37. Proximity of GHs to higher level hospitals (THs)

Figure 38. Number of DHs within catchment of each $\mathrm{BH}$

Figure 39. Number of DHs feeding to BHs within districts 
Figure 41. Number of DHs and BHs feeding to GHs within districts

Figure 42. Number of DHs, BHs, and GHs within catchment of each TH

Figure 43. Number of DHs, BHs, and GHs feeding to THs within districts

Figure 44. Distance from hospitals to nearest main road

Figure 45. Distance from DHs to nearest main road

Figure 46. Mean of the distances from DHs to nearest main road in each district

Figure 47. Distance from BHs to nearest main road

Figure 48. Mean of the distances from BHs to nearest main road in each district

Figure 49. Distance from GHs to nearest main road

Figure 50. Mean of the distances from GHs to nearest main road in each district

Figure 51. Distance from THs to nearest main road

Figure 52. Mean of the distances from THs to nearest main road in each district 


\section{Acknowledgements}

I greatly appreciate the cooperation extended by the Deputy Director General / Health Information Unit of Ministry of Health in granting permission to access the updated list of hospitals for this study. The assistance of Mr. Prabath Malawige and Prof. RMK Rathnayaka in obtaining the digitised one-inch and metric map layers was imperative in the success of this research. The guidance offered by Prof. Krishan Deheragoda and Mr. Malawige to successfully complete this research is also highly appreciated. 


\title{
Analysis of Geospatial Distribution of State-Sector Hospitals in Sri Lanka
}

by

BCV Senaratna

\begin{abstract}
The extremely favourable healthcare indices that Sri Lanka has today are mainly the result of dedicated and efficient preventive healthcare work. Nevertheless, the curative healthcare institutions (hospital and dispensaries) have also contributed to minimise disease complications and mortality. However, the adequacy (or inadequacy) of hospitals to the people in various districts and equitable (inequitable) nature of their distribution have not been recently studied.
\end{abstract}

The objectives of this study were to describe the distribution of state-sector hospitals in Sri Lanka and its relationship to the population density of the relevant districts and to determine the proximity of these institutions to each other and accessibility through the existing road network.

This study was conducted by analysing secondary data and data created/derived from secondary sources. The analysis was done using ArcGIS 10.1 software. The distribution of all types of hospitals as well as hospitals of different categories across the districts were analysed and were correlated with the populations and population densities of those districts. The catchment populations of each hospital were determined and compared within districts. The relative proximities of hospitals to each other, the proximity of higher-grade hospitals to the relatively lower-grade hospitals, and the extent of drainage of smaller hospitals to larger hospitals were analysed. The accessibility of hospitals were determined using their comparative distances from the main roads. 
There were district variations in the number of hospitals. Three western districts had the least number of hospitals for a unit population (more than 60,000 using one hospital). Majority of hospitals in the country catered to a population of less than 25,000 and many others a population of 25,000-50,000, except in the western districts $(300,001-500,000)$. Most districts of the Northern Province had the least number of people per hospital. While the hospitals in two and three of the northern districts have to accommodate 150 or less and 201-300 people in a bed, respectively, those in the majority of other districts have to accommodate 301-500 people in a bed.

Most of the hospitals (regardless of their category) were located within $5 \mathrm{~km}$ from its nearest other hospital. Most DHs have a higher grade hospital within 5-15 km. Similarly, most BHs had a GH or a TH within $5-20 \mathrm{~km}$. Most GHs had a TH within $60 \mathrm{~km}$. Further, most BHs had 1-5 or 6-10 DHs feeding them and a large majority of GHs have 21-50 BHs or DHs feeding to them.

The large majority of the hospitals were located at either less than $1 \mathrm{~km}$ or $1.1-5 \mathrm{~km}$ from a main road. Majority of DHs, BHs, GHs, and THs were located within $5 \mathrm{~km}, 1-2 \mathrm{~km}, 0.5 \mathrm{~km}$, and $0.3 \mathrm{~km}$, respectively, from main roads.

Although there is no systematic variation in the number of hospitals (total and of different categories) between districts, the hospitals in western and southern regions of the country have to accommodate more people compared to those in the northern regions and few other areas. All hospitals are located close to each other thus facilitating people to access healthcare easily. The distances between different types of hospitals were at a satisfactory level, and most smaller hospitals and all larger hospitals are easily accessible through the network of main roads. 


\section{Introduction}

\subsection{Evolution of healthcare services in Sri Lanka}

The history of healthcare in Sri Lanka dates back to the pre-historic era (Survey Department of Sri Lanka, 2007, Wickramasinghe, 2001). Since ancient times, Sri Lanka boasted of an excellent healthcare delivery system, both preventive and curative, including most advanced sanitary and sewage treatment systems at the time and diversified specialties such as surgery, gynaecology, dermatology etc. . These healthcare services in ancient times were provided by a network of state-sponsored system of small and large hospitals, and well as by private practitioners. However, this excellent system began to falter after the $13^{\text {th }}$ century $\mathrm{AD}$, consequent to the repeated and brutal Indian invasions the Sinhala kingdom suffered during this period (Wickramasinghe, 2001). After the $16^{\text {th }}$ century AD, indigenous healthcare delivery system suffered further setbacks due to the Western invasions, and was destroyed to a large extent after the 1818 rebellion. Simultaneously, the allopathic healthcare system was established in the coastal areas of Sri Lanka that were dominated by the Portuguese at first, and by the Dutch and the British later. Since the establishment of first Portuguese hospital for their soldiers in the $16^{\text {th }}$ century, the allopathic system gradually became the dominant healthcare system in Sri Lanka over the next few centuries, and at present, provides both curative and preventive healthcare services to all people of Sri Lanka (Survey Department of Sri Lanka, 2007, Wickramasinghe, 2001). Although the traditional and alternative healthcare systems continue to provide healthcare to the people, the state-sponsored, free, allopathic system has almost exclusively contributed to the 
appreciable advances in the healthcare delivery that are seen at present (Ministry of Health, 2011, Wickramasinghe, 2001, Survey Department of Sri Lanka, 2007).

\subsection{Present status and classification of state-sector healthcare services}

State-sector healthcare delivery system in Sri Lanka consists of two interconnected and widely-distributed networks of preventive and curative institutions, which penetrates in to most remote regions of the country (Ministry of Health, 2011, Survey Department of Sri Lanka, 2007). As result of this wide availability of healthcare to the population, Sri Lanka at present has extremely favourable indices to describe the quality of its healthcare provision to the population (World Health Organisation, 2013b). By the year 2010, Sri Lanka's infant mortality rate, maternal mortality ratio, and under-five mortality rate, which are some of the major indices for quality of healthcare provision in a country, stood at 9.2 per 1000 live births, 3.5 per 10,000 live births, and 12 per 1000 children under 5 years of age, respectively, and were much favourable than those of all other countries in the South Asian region (World Health Organisation, 2013b). This success in healthcare is built on the aforementioned free healthcare services complimented by free education provided to the Sri Lankan people, which, respectively, increased the healthcare provision to individuals and communities and facilitated to achieve high female literacy rate and health literacy rate (World Health Organisation, 2013a, Department of Census and Statistics Sri Lanka, 2008).

The success story in terms of health indices in Sri Lanka is largely due to the primary and primodial prevention through efficient and comprehensive network of preventive healthcare 
services (Ministry of Health, 2011, Survey Department of Sri Lanka, 2007, Wickramasinghe, 2001). At national level the preventive healthcare services are delivered through institutions such as Family Health Bureau, Epidemiology Unit, Health Education Bureau, and Special Campaigns to control specific diseases such as malaria, dengue, filariasis, tuberculosis, rabies, leprosy, sexually-transmitted diseases and HIV/AIDS. At regional/local level the preventive services are carried out through midwives and public health inspectors attached to the Medical Officer of Health divisions. The dedication of the preventive health staff and the timely and accurate communications between these national and local institutions that facilitate outstanding surveillance mechanism had been fundamental in achieving many success stories in health (Department of Census and Statistics Sri Lanka, 2008, Ministry of Health, 2011, Survey Department of Sri Lanka, 2007, World Health Organisation - Country Office for Sri Lanka, 2013).

Nevertheless, the development and wide availability of curative healthcare institutions to the local communities across the country has also played a role in minimising complications of diseases and deaths due to illnesses (Department of Census and Statistics Sri Lanka, 2008, World Health Organisation - Country Office for Sri Lanka, 2013, Ministry of Health, 2011, Survey Department of Sri Lanka, 2007). Improved availability of curative healthcare services meant that people had rapid access to required treatment when the primary prevention was unsuccessful, and thereby prevented mortality and disability to a great extent. 